\title{
Caring for Patients with Limited English Proficiency: The Perspectives of Small Group Practitioners
}

\author{
Margaret Gadon, $\mathrm{MD}, \mathrm{MPH}^{1,2,3}$, George I. Balch, $\mathrm{PhD}{ }^{4,5}$, and Elizabeth A. Jacobs, MD, MPP 6,7 \\ ${ }^{1}$ American Medical Association, Chicago, IL, USA; ${ }^{2}$ Northwestern University, Evanston, IL, USA; ${ }^{3}$ University of Illinois School of Public Health,

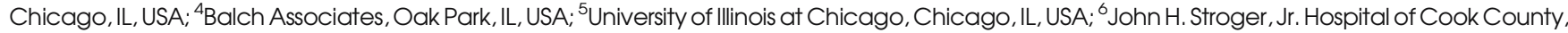 \\ Chicago, IL, USA; ${ }^{7}$ Rush University Medical Center, Chicago, IL, USA.
}

\begin{abstract}
BACKGROUND: Language barriers in medical care are a large and growing problem in the United States. Most research has focused on how language barriers affect patients. Less is known of the physician perspective and the efforts they are making to overcome these barriers.
\end{abstract}

OBJECTIVE: To learn about current approaches to communicating with limited English-proficient (LEP) patients and the associated financial and nonfinancial constraints that private practice physicians and managers perceive in providing these services.

DESIGN: Computer-assisted telephone focus groups with open-ended discussion guide.

SETTING: Small private practices in geographic areas that have experienced recent dramatic increases in LEP populations.

PARTICIPANTS: Primary care physicians, specialists, and practice managers.

APPROACH: Focus group transcripts were systematically coded using grounded theory analysis. The research team then identified common themes that arose across the groups.

RESULTS: Citing the cost, inaccessibility, and inconvenience of using professional interpreters, physicians commonly used family and friends as interpreters. Few recalled any actual experience with professional interpreters or were well-informed about the cost of their services. Physicians and office managers voiced uniform concern about how language barriers impede quality and safety of patient care and increased malpractice risk.

CONCLUSIONS: Health care providers in private practice recognize the importance of overcoming language barriers. However, perceived barriers to implementing cost-effective strategies to these barriers are high. Physicians in private practice would benefit from information about how to best overcome language barriers in their practices efficiently and affordably.

KEY WORDS: interpreter; language barrier; limited English proficient; physician; telephone focus groups.

J Gen Intern Med 22(Suppl 2):341-6

DOI: $10.1007 / \mathrm{s} 11606-007-0311-4$

(c) Society of General Internal Medicine 2007

The work described in this paper was presented at the 29th annual meeting of the Society of General Internal Medicine, May, 2006.

\section{INTRODUCTION}

The 2000 U.S. Census reported that 47 million residents speak a language other than English at home, and almost half of them speak English less than "very well" by the U.S. Census definition. This limited English proficient (LEP) population is projected to increase dramatically by the year 2010, and immigrants and refugees are increasingly settling in areas of the country with relatively homogeneous English speaking populations ${ }^{1}$. This has created a situation in which many physicians previously unaccustomed to addressing language barriers in their practices now face the challenge of communicating across a language gap.

Many health care systems and physician offices have responded to the challenge of communicating with LEP patient populations by using a variety of interpreters. They provide language access services in the form of face-to-face and telephonic professional interpreters and trained bilingual staff, rely on "ad hoc" interpreters such as untrained bilingual staff, and family and friends. ${ }^{2}$ Despite the fact that research has highlighted the poor quality of "ad hoc" interpretation and that it likely increases medical errors ${ }^{3-7}$, physicians are reluctant to work with professional interpreters, citing their cost and inefficiency ${ }^{8}$. However, it is not clear that physicians perceive the risks of using ad hoc interpreters in terms of patient safety, the advantages of working with professional interpreters, and the actual costs of these services.

In 2005, the American Medical Association (AMA) decided to probe this issue more fully by conducting focus groups with physicians in small group practices in areas with large, recent LEP growth. Unlike areas with long-established immigrant enclaves, the areas with new LEP growth are less likely to have well-developed resources, policies, or practices in place to help office physicians address language barriers. The aim of the study was to learn about current approaches to communicating with LEP patients and the associated nonfinancial and financial constraints experienced by small private practitioner groups who provide these services.

\section{MATERIALS AND METHODS}

Nine computer-assisted telephone (CAT) focus groups were conducted in October and November of 2005. CAT focus groups allow the moderator to tell who is speaking at any time, and they permit geographically dispersed people to converse and be recorded simultaneously without having to leave home or the office ${ }^{9-11}$. Three focus groups were con- 
ducted with General Internists and family practitioners (primary care physicians or PCPs; $n=24$ ), three with specialists in practices that involve sustained direct communication with patients $(n=21$; Table 1$)$, and three with office managers $(n=22$; Table 1). We included office managers in this study because we hypothesized that they would have unique insight into the financial and system barriers to using professional interpreters in the practice.

Participants were recruited from lists obtained from the AMA Master file of all physicians in primary care and specialty practices of 4 to 9 practitioners whose offices were located in the 15 states that scored highest on 2 indices of growth in LEP population between the 1990 and 2000 U.S. Census. One index was the percentage change in LEP populations in that period. The second index was the first index multiplied by the 2000 U.S. Census percentage of each state's population that was foreign born. The second index was formulated on the assumption that recent migrants have the greatest need for language support. Additional physician participants were recruited by referral from contacted physicians.

A professional market research recruitment firm contacted all practices on the lists by fax. The fax briefly described the research study and its goals, noted that an honorarium would be paid for qualified participants, and requested that interested physicians and office managers contact the recruiter. The recruiter administered a screening questionnaire to those who contacted him and invited those who qualified to participate in a confidential telephone discussion group. Physicians and practices qualified if the physician practiced in their office at least 20 hours/week, saw adult patients as at least $50 \%$ of their patient load, saw "some" limited English-speaking patients (LEP) at least weekly, and agreed that their practice sometimes needed or wished to have interpretation for these office visits. Qualified participants $(n=62)$ were also asked to refer others; 5 participants were screened and added by this "snowballing" process. All 5 of them were from states that scored high on the index of recent growth in LEP population. All participants were from places not historically known for high concentrations of immigrants.

All 90-minute CAT focus group sessions were moderated by a veteran focus group moderator (GB), working from a semistructured discussion guide. All sessions were also

Table 1. Specialties and Locations of Focus Group Practices

\begin{tabular}{ll}
\hline \hline Specialties & States \\
\hline Allergy and immunology & Arizona \\
Cardiology & California \\
Dermatology & Colorado \\
Endocrinology & Delaware \\
Family practice & Georgia \\
Gastroenterology & Idaho \\
General internal medicine & Kansas \\
General surgery & Minnesota \\
Nephrology & Nebraska \\
Obstetrics-gynecology & Nevada \\
Orthopedic surgeon & New Hampshire \\
Physical & North Carolina \\
Medicine/rehabilitation & Oklahoma \\
Plastic surgery & South Carolina \\
Psychiatry & Tennessee \\
Pulmonology & Utah \\
& Virginia \\
& Washington \\
\hline
\end{tabular}

audited telephonically by the first author, audiotaped, and transcribed with participants' consent. The discussion guide covered three main topics in depth: (1) concerns about communicating with LEP patients; (2) their current practices for communicating with LEP patients and the perceived benefits and drawbacks of each; and (3) how they perceive and deal with the costs of interpreter services. The research was approved by the Western International Review Board.

Our analysis was guided by the grounded theory perspective to glean information from the participants' perspectives rather than testing empirical assumptions or hypotheses ${ }^{12}$. In this type of analysis, codes are derived from review of the transcripts and then applied to all transcripts rather than developing codes based on initial hypotheses and theories and then applying them to the transcripts. Initial codes were developed by the first author (MG) and the moderator/author (GB) based on debriefings and transcripts from the first 2 focus groups. Further codes were added as additional focus group transcripts were reviewed, and additional themes emerged. All transcripts were then read and coded independently for themes by these 2 authors, with a high level of agreement. Disagreements between the 2 coders were resolved by discussion until a consensus was reached on how to apply a code or interpret a theme.

Pattern themes, defined as concepts that occurred frequently across all 9 groups, were identified from the analysis of the coded text. We report the qualitative results by summarizing the overall themes that occurred across all groups and providing 1 or 2 quotes representative and illustrative of the themes.

\section{RESULTS}

A total of 67 individuals participated in the 9 focus groups: 45 physicians, each from a different practice (24 PCPs and 21 specialists), and 22 office managers, several of whom were from practices of the physician sample. Each group included 7-8 participants. Twenty-six participants were female and 41 were male. Most of the female participants were office managers (22 of 26), and all of the 41 male participants were physicians. Specialist physicians represented 13 different surgical and nonsurgical specialties (Table 1). Participants came from 34 counties in 18 states (Table 1), none of which had a long history of supporting immigrant populations. Whereas Spanish was the most common non-English language that these practices encountered among LEP patients, physicians and office managers indicated a total of 24 other languages spoken by patients of their practices. Several major themes emerged from the data analysis and fall into 3 broad categories: (1) motivations for and perceptions of commonly used methods of communication, (2) physician and office manager concerns about caring for LEP patients, and (3) perceptions of the costs of providing language access services.

\section{Motivations for and Perceptions of Commonly Used Methods of Communication}

Method of Communication Selected was Driven by Practical Concerns. Family and friends were by far the most common form of interpreter assistance used by practices in this study. Next, in order of descending, reported frequency were: 
bilingual, administrative office staff who were untrained in professional interpretation; bilingual, clinical office staff untrained in professional interpretation; bilingual physicians; and nonprofessional volunteers, often church-affiliated from the community. Participants' perceptions of the advantages and disadvantages of working with these different interpreters are summarized in Table 2.

Participants who used ad hoc services cited availability, cost, and the interpreter's familiarity with the patient's dialect and culture as the reasons for their use. They used bilingual staff for similar reasons. One common concern about the use of bilingual office staff was that the dual job responsibilities interrupt the staff's work flow at times. The lack of medical training of the nonclinical staff and the lack of professional interpreter training of both clinical and nonclinical staff led to concerns about the reliability and accuracy of interpretation.

Providers perceived bilingual physicians as most effective and efficient at conducting the medical portion of the visit and a scarce resource. Some envisioned that bilingual providers could build a specialized business to serve bilingual patients. Some office managers and physicians in the focus groups, however, expressed concern about an unbalanced load in group practices that might overwhelm the bilingual physician.

Professional interpreters were more often used in specialty practices and in a few primary care practices when physicians had frequent contact with patients who spoke a non-English language. Focus group participants were neither able to quantify the number of LEP patients for whom they provided medical care nor estimate the amount of time that professional interpreters would be routinely needed to maintain a smoothly running practice.

The few physicians who had used telephonic interpreter services-primarily specialists who had encountered them in the hospital-appreciated the availability of multiple languages and professional interpreters who might be versed in medical terminology. However, they were concerned about the associated extra time and perceived inconvenience involved, as well as with the impersonal quality they imputed to this kind of interpreter service. Some expressed concern over a loss of nonverbal input from the patient in the absence of a face-toface encounter, and others were not even aware of the existence of telephonic services. Several physicians and practice managers, also without telephonic interpreter service experience, anticipated barriers to the use of telephonic interpreters, such as absence of phone jacks or of multiple phones in examination rooms.

Ambivalence Toward Use of Untrained Interpreters. Although ad hoc interpreters were commonly used, the focus group participants did admit to concerns about loss of confidentiality, incompleteness and inaccuracy of interpretation, inappropriateness of young children interpreting for some health issues, and increased physician liability when they worked with an untrained interpreter, especially when obtaining informed consent. This is well illustrated in the following quote:

I think my biggest concern is things that (get) lost in the translation and whether ...in our case usually the translator is a family member and I think sometimes they edit both what the patient says and what I say. So I'm not sure always how clear the communication is. (female PCP)
Table 2. Perceptions of Language Access Services Most Frequently Used in Small Physician Practices

\begin{tabular}{|c|c|c|}
\hline $\begin{array}{l}\text { Type of } \\
\text { interpretation/ } \\
\text { translation }\end{array}$ & $\begin{array}{l}\text { Perceived } \\
\text { advantages }\end{array}$ & $\begin{array}{l}\text { Perceived } \\
\text { disadvantages }\end{array}$ \\
\hline \multirow[t]{5}{*}{$\begin{array}{l}\text { Family/friends } \\
\text { (ad hoc) }\end{array}$} & Most readily available & $\begin{array}{l}\text { Breaches } \\
\text { confidentiality, privacy }\end{array}$ \\
\hline & Cost-free & $\begin{array}{l}\text { Do not interpret all } \\
\text { information }\end{array}$ \\
\hline & $\begin{array}{l}\text { Familiar with patient, } \\
\text { language, culture }\end{array}$ & May not be accurate \\
\hline & & $\begin{array}{l}\text { Some are inappropriate } \\
\text { for some health issues } \\
\text { (e.g., child) }\end{array}$ \\
\hline & & $\begin{array}{l}\text { Increase liability, } \\
\text { especially for informed } \\
\text { consent }\end{array}$ \\
\hline \multirow[t]{6}{*}{$\begin{array}{l}\text { Nonclinical } \\
\text { bilingual staff }\end{array}$} & $\begin{array}{l}\text { Available in some } \\
\text { communities }\end{array}$ & $\begin{array}{l}\text { Not available in some } \\
\text { communities }\end{array}$ \\
\hline & $\begin{array}{l}\text { No relationship to } \\
\text { patient }\end{array}$ & $\begin{array}{l}\text { Conflicts with their } \\
\text { other work }\end{array}$ \\
\hline & $\begin{array}{l}\text { Can interpret some } \\
\text { administrative } \\
\text { functions }\end{array}$ & Not always available \\
\hline & & Not medically trained \\
\hline & & $\begin{array}{l}\text { May not be accurate } \\
\text { in interpreting }\end{array}$ \\
\hline & & $\begin{array}{l}\text { Only one non-English } \\
\text { language }\end{array}$ \\
\hline \multirow[t]{5}{*}{$\begin{array}{l}\text { Clinical } \\
\text { bilingual staff }\end{array}$} & $\begin{array}{l}\text { Available in some } \\
\text { communities }\end{array}$ & $\begin{array}{l}\text { Not available in some } \\
\text { communities }\end{array}$ \\
\hline & $\begin{array}{l}\text { No relationship to } \\
\text { patient }\end{array}$ & $\begin{array}{l}\text { Conflicts with their } \\
\text { other work }\end{array}$ \\
\hline & $\begin{array}{l}\text { Medically trained and } \\
\text { familiar with } \\
\text { doctor's process }\end{array}$ & Not always available \\
\hline & Can be cost-efficient & $\begin{array}{l}\text { May not be accurate } \\
\text { in interpreting }\end{array}$ \\
\hline & & $\begin{array}{l}\text { Only one non-English } \\
\text { language }\end{array}$ \\
\hline \multirow[t]{3}{*}{$\begin{array}{l}\text { Bilingual } \\
\text { physicians }\end{array}$} & $\begin{array}{l}\text { Most effective and } \\
\text { efficient }\end{array}$ & Few available \\
\hline & $\begin{array}{l}\text { Best if physician is } \\
\text { also bicultural }\end{array}$ & $\begin{array}{l}\text { Load can overwhelm the } \\
\text { bilingual physician }\end{array}$ \\
\hline & $\begin{array}{l}\text { Can build a } \\
\text { specialized business }\end{array}$ & $\begin{array}{l}\text { Can create load } \\
\text { imbalance with } \\
\text { colleague practitioners }\end{array}$ \\
\hline \multirow{6}{*}{$\begin{array}{l}\text { Professional } \\
\text { interpreters (in } \\
\text { person) }\end{array}$} & $\begin{array}{l}\text { More complete than } \\
\text { family/friends }\end{array}$ & Cost \\
\hline & $\begin{array}{l}\text { More accurate than } \\
\text { family/friends }\end{array}$ & $\begin{array}{l}\text { Pay for time beyond } \\
\text { actual visit (travel, } \\
\text { waiting) }\end{array}$ \\
\hline & $\begin{array}{l}\text { Different languages } \\
\text { available }\end{array}$ & $\begin{array}{l}\text { Interpreter may } \\
\text { not be reliable }\end{array}$ \\
\hline & & $\begin{array}{l}\text { No check on quality, } \\
\text { accuracy }\end{array}$ \\
\hline & & Know medical terms? \\
\hline & & HIPAA compliant? \\
\hline \multirow[t]{8}{*}{$\begin{array}{l}\text { Telephonic } \\
\text { interpreting }\end{array}$} & $\begin{array}{l}\text { Many languages } \\
\text { available }\end{array}$ & Provider unaware of it \\
\hline & $\begin{array}{l}\text { May know medical } \\
\text { terms }\end{array}$ & $\begin{array}{l}\text { Provider unfamiliar } \\
\text { with it }\end{array}$ \\
\hline & $\begin{array}{l}\text { Fast to access } \\
\text { interpreter }\end{array}$ & Cost \\
\hline & $\begin{array}{l}\text { Objective/ } \\
\text { professional }\end{array}$ & Lengthens visit \\
\hline & & $\begin{array}{l}\text { Rooms lack phone jack, } \\
\text { multiple phones }\end{array}$ \\
\hline & & $\begin{array}{l}\text { Inconvenient: passing } \\
\text { phone between } \\
\text { physician and patient }\end{array}$ \\
\hline & & No patient body language \\
\hline & & May not know dialect \\
\hline
\end{tabular}


Use of Standardized Tools to Compensate for Lack of Language Concordance. The practices also used a variety of nonpersonnel-related tools to facilitate communication with patients, such as electronic health records with multilingual patient handout capabilities, handheld translators, preprinted forms and drug information, books with multilingual medical phrases, and "cheat sheets" with translations of words and phrases commonly used in the patient-physician interaction. These aids clearly had limitations. For example, one physician who saw a large volume of Hispanic patients found that the sheets did not have sufficient depth to provide an accurate representation of the patient's complaints.

I also have a cheat sheet that I use. But there are some scary situations. I had a sort of frightening situation with that a few days ago...I thought I had the patient diagnosed and ...was headed out and said "well, let me just get the translator to make sure" and (it turned out that) there was another major problem that we need to address. (male PCP)

\section{Physician and Office Manager Concerns}

The Impact of Communication Barriers on the Quality of Patient Care. Almost all of the physicians expressed concerns about the impact of communication barriers on the quality of patient care. Specifically, they voiced concerns about their inability to obtain a detailed and accurate medical history to effectively communicate the treatment plan and the details of procedures for which to obtain informed consent and the excess time they felt they needed for the care of LEP patients. One surgeon described it in the following way:

Usually, in our office, it's one of our office staff who is acting as an interpreter ... or a family member. But my biggest concern is that they truly don't understand what I'm telling them. Don't understand the breadth of their illness or trying to give informed consent for Surgery. I feel like I'm doing an inadequate job. I'm not getting the whole story across to them as I would want to. (male surgeon)

Coexistent Cultural Barriers. Many physicians voiced an awareness that when caring for LEP patients, there were cultural as well as linguistic barriers. Most commented that both of these barriers need to be addressed to provide effective delivery of high quality care. A particular concern was how to deal with differences in cultural orientations to taking medications, as in this example:

In the older patient, particular, trying to get across what the symptoms are. ... I have a patient ... an elderly Chinese lady with a complex cardiac problem and is on Coumadin and trying to get her to take the Coumadin and not take her Chinese herbs which interact with the Coumadin and dealing with those cultural issues. Those are real problems because they will use their cultural heritage because they believe in it strongly and they may or may not tell you that they're doing that. (male PCP)
Liability Concerns. Concerns about physician liability as a result of this diminished quality of care were paramount, particularly among the office manager group and specialists. Indeed, liability was a major reason for some physicians to use a professional interpreter rather than family and friends. Yet, some physicians also had concerns about the quality and HIPAA compliance of interpretation of even the professional interpreters and questioned the need for some sort of "certification" for these individuals.

Specialists often anticipated their patients' need for interpreters and scheduled them in advance when they were available. Several physicians stated that they make notes in the medical chart about the conversations to protect themselves and be able to show, if needed, that the fault of miscommunication lies with the interpreter. As this specialist said:

\begin{abstract}
The other thing that I'm also concerned about is medical legal things. So we have several people in our office who speak Spanish ... so I always get the name of the person down that is helping the translation just in case I need to go back and review my notes and answer questions from an attorney. (Male Ob-Gyn physician)
\end{abstract}

PCPs, conversely, voiced less unease about liability issues than did most of the specialists. The barriers of high cost and inconvenience outweighed their concerns in this area.

Unfair Burden for Physicians. An undercurrent of all focus groups was frustration in caring for a population for which they found themselves unprepared and underresourced. Whereas some noted that it was their professional responsibility to provide health care for all, even these physicians acknowledged that the feasibility of providing this beyond a certain volume of patients was limited. Physicians also noted that frustrations occurred on the part of the patient as well as the physician.

If I can't get a history from a patient ... if the patient can't give me a history I cannot explain to the patient what the problem is. It's a zero encounter ... it's a waste of time and nobody gets anything out of it. (Male nephrologist)

\section{Perceptions of the Costs of Language Access Services}

High Perceived Costs of Language Access Services. In every group, participants made frequent spontaneous comments about the high cost of interpreter services. Yet, few of the physicians or managers had experience using and paying for professional interpreter services on which to base their perceptions. None knew exactly how many LEP visits their office had over a period of a year and therefore their service need. Few recalled having ever paid for interpreter services. Most had never investigated the costs of contracting with remote or on-site interpreters. Estimated costs by office managers varied from $\$ 30$ in some groups to $\$ 200$ per visit in others. When pressed about how much they would be willing to pay for a language service to ensure good quality of 
communication, office managers had difficulty justifying any cost whatsoever. As these two office managers said:

You would have to do a cost analysis because you're going to lose money. These people don't pay you and you pay someone to interpret and you're losing your money in both directions.

...[T]the doctors would just rather that patient go somewhere else[and] find a solution somewhere else. The new doctor just starting out ... ...(they) deal with it. Any established practice is going to try to avoid that.

\section{Ad Hoc Strategies For Coping with the Cost of Language} Access Services. Some physicians were aware of the cost of these services and had developed methods for providing the services without incurring any additional costs to their practices. One mentioned that he received supplemental federal funding to care for his LEP population, on the basis of their being "uninsured." Several physicians noted that they could use the interpreters at the hospital with which they were affiliated free of charge. A few others discussed the possibility that caring for LEP patients with the use of a professional interpreter or bilingual providers could be a profitable venture if the volume of these patients who spoke one non-English language were sufficiently high

\section{DISCUSSION}

Although the United States developed as a nation of immigrants, services offered in the public and private sector have traditionally all been in English. In areas of the country with high concentrations of LEP populations, health care providers and organizations have frequently responded by providing health care services in languages other than English. However, many new immigrant populations are also settling in areas of the country traditionally populated by monolingual English speakers. In the states of Arkansas, Georgia, Nevada, Oregon, Utah, and North Carolina for example, the LEP population increased by more than 100\% between the 1990 and 2000 censuses $^{1}$. Our study highlights how physicians and health systems respond to this new, dramatic growth. They have little real knowledge about overcoming language barriers or tools to help them respond to this growing need and worry about the impact of language barriers on the quality of care and their liability.

Our findings replicate those of other focus group studies of physicians in small group practices who care for LEP patients, though not in areas of recent high LEP and foreign-born population growth ${ }^{8,13}$. Our study sheds additional light on the lack of both physicians' and practice managers' knowledge of the cost of language services, their differential patterns of use by PCPs and specialists, and the level of frustration physicians and practice managers experience when faced with the new challenge of taking care of LEP patients.

Physicians and practice managers in this study clearly understood that language barriers can reduce the quality and safety of care for LEP populations. Many also recognized that the quality of communication is compromised when ad hoc interpreters are used. Yet, few physicians, particularly those in primary care, utilized professional interpreters in practice other than in settings of high liability concerns. Although this may be due in part to the limited information physicians voiced about how to access professional interpreter services and use them efficiently and affordably, our findings also suggest that physician concerns about quality of care are outweighed by the perceived cost and inconvenience of using these services.

Primary care providers and specialists voiced different ways of addressing the balance between liability and cost concerns. Several specialists voiced a greater willingness to "absorb" the cost of interpreter services than did primary care providers. This may relate to several factors: the higher reimbursement rates the specialists receive for their services, their higher exposure to liability, or the fact that they typically do not have a sustained relationship with the patients.

Most physicians and office managers in this study were not well versed on the types of interpreter services available or available resources such as telephonic interpreter services. Multiple resources describing strategies to address language barriers are now available to physicians and practice managers, although statistics on how or to what extent these have been marketed are not available. These resources include a toolkit by the California Academy of Family Physicians for addressing language issues in practice, a pamphlet from the American Medical Association on practical tips for physicians who care for LEP patients, and a toolkit for collecting primary language data by the Health Resources Educational Trust ${ }^{14-16}$. In addition, a recent study sponsored by the Commonwealth Fund identified feasible strategies for addressing language barriers in 18 self-selected small group practices, including staff training on the use of interpreters, the hiring and training of bilingual staff, bulk negotiation of interpreter contracts, among others ${ }^{17}$. In terms of cost estimates, there are some data from a nationwide study done by the Office of Management and Budget study $^{18}$. Average costs were determined to be $\$ 26$ per hour for staff, \$20 per hour for community "language banks," and \$132 per hour (which could be prorated) for telephonic interpreters. This is useful as a guideline, although costs do vary across geographic areas.

The findings of our study also bring to light the high level of physician frustration with caring for LEP patients. This frustration led to consideration by some physicians and practice managers to abandon care of LEP patients in their practices. This finding has important policy implications. Physicians and practice managers need better resources and support when faced with taking care of new populations of LEP populations so as to reduce this frustration and increase the likelihood that they will accommodate rather than abandon care of patients challenged by language barriers. Medical organizations at the federal, state, and county level should promote innovative solutions to funding for language access services for their physician members. National professional medical societies should advocate for interpreter standards and certification. In addition, physician training on how to best work with interpreters would be beneficial. This type of training has been shown to increase use of trained interpreters ${ }^{19}$.

There were some limitations to this study. The sampled practices were likely not representative of all small private 
practices in the United States. The sample was a purposive one, comprised of practices in areas of relatively high growth in LEP populations that currently see patients for whom they need interpretation and translation. In view of recent immigration trends, this sample is a vanguard of what more practices may come to experience. In addition, we did not have data on existing language services in each practice area to validate perceptions of the "lack of resources" or the types of interpreters that the physicians said they used.

The results of these focus groups make clear that physicians and office managers understand the problems that language barriers and using ad hoc interpreters pose to providing efficient and effective care for the LEP population. They also reinforce the need for more effective health policy and advocacy efforts to provide physicians and office managers with training about and resources for the provision of feasible approaches to addressing communication barriers, which address liability, inconvenience, and cost concerns. In the absence of such strategies, physician practices may see no other choice than to limit the access of LEP patients to their practices. This study highlights the need for new models of resource sharing for language access services by physician groups and research into the cost-effectiveness and safety of these models. Policy development on standards of practice for professional interpreters would also be beneficial. Whereas many of the physicians in this study find little incentive today to address this issue, recent population trends suggest that many more physicians nationwide will need to consider the language access needs of their patients in the near future.

Acknowledgments: We thank the members of the AMA External Advisory Group on Language, Kimball P. Marshall for designing the sampling frame, Derek Smart for providing the population data, Scott Bass for recruiting participants, and our focus group participants for their cooperation. Dr. Jacobs was supported by a National Cancer Institute (\#5K07CA089421-03) and a Robert Wood Johnson Generalist Physician Faculty Scholar award during this research.

Conflict of Interest Statement: None Disclosed.

Corresponding Author: Margaret Gadon, MD, MPH; American Medical Association, 515 N. State Street, Chicago, IL, 60610, USA (e-mail: margaret.gadon@ama-assn.org).

\section{REFERENCES}

1. U.S. Bureau of the Census. Profile of selected social characteristics (Table DP-2). Available at http://factfinder.census.gov 2000.

2. Brach C, Fraser I, et al. Crossing the language chasm. An in-depth analysis of what language-assistance programs look like in practice. Health Affairs 2005;24(2):424-34.

3. Karliner LS, Jacobs EA, et al. Do professional interpreters improve clinical care for limited English proficiency patients? A systematic review of the literature. Health Services Research DOI 10.1111/j. 1475-6773.2006. 00629.x 2007 (published on-line August 31, 2006).

4. Flores G, Laws MB, Mayo SJ, et al. Errors in medical interpretation and their potential clinical consequences in pediatric encounters. Pediatrics 2003;111(1):6-14.

5. Price CS, Cuellar I. Effects of language and related variables on the expression of psychopathology in Mexican American psychiatric patients. Hisp J Behav Sci 1981;3:145-60.

6. Vasquez C, Javier R. The problem with interpreters: communicating with Spanish-speaking patients. Hosp Commun Psychiatry 1991;42(2):163-5.

7. Ghandi TK, Burstin HR, Puopolo JS, et al. Drug companies in outpatients. J Gen Intern Med 2000;15:149-54.

8. Lake Snell, Perry, Mermin and Associates, Ltd. Physician perspectives on communication barriers. Insights from focus groups with physicians who treat non-English proficient and limited English proficient patients. Prepared for the Robert Wood Johnson Foundation, Princeton, NJ; 2004.

9. Balch GI. C.A.T. (Computer-Assisted Telephone) focus groups: better, faster, cheaper focus groups for the "hard-to-reach." Soc Mark Q 2001;7(4):38-40.

10. Silverman G. Introduction to telephone focus groups. Available at http://www.mnav.com/phonefoc.htm 2003 (last accessed Aug 7, 2006).

11. Hurwith R. Telephone focus groups. Soc Res Update 2004;44:1-7. Available at: http://www.soc.surrey.ac.uk/sru/SRU44.html. Accessed Aug 7, 2006.

12. Glaser B, Strauss A. The discovery of grounded theory: strategies for qualitative research. New York: Hawthorne; 1967.

13. American Institutes for Research. Health care professionals' perspectives on the content and structure of the draft health care language services implementation guide. Washington, DC, U.S.: Office of Minority Health; 2005.

14. California Academy of Family Physicians. Addressing language issues in your practice. A toolkit for physicians and their families. Available at http://www.familydocs.org/toolkits.php.

15. American Medical Association. Clinicians' guide to language services for limited English-proficient patients. Chicago: American Medical Association; 2005.

16. HRET. A toolkit for collecting race, ethnicity and primary language data from patients. Available at: http://www.hretdisparities.org/hretdisparities_app/ index.jsp (Last accessed March 20, 2007).

17. Youdelman M, Perkins J. Providing language services in small health care provider settings: examples from the field. Field report for the Commonwealth Fund, 810. New York: Commonwealth Fund; 2005.

18. Office of Management and Budget. Report To Congress. Assessment of the total Benefits and costs of implementing Executive Order no. 13166: improving Access to services for persons with limited English proficiency. Available at: www.whitehouse.gov/omb/inforeg/lepfinal3-14.pdf 2002 (Accessed June 23, 2007).

19. Karliner LS, Perez-Stable EJ, Gildengorin G. The language divide: the importance of training in the use of interpreters for outpatient practice. J Gen Intern Med 2005;9(2):175-83. 